https://helda.helsinki.fi

\title{
Impact of systemic diseases and tooth-based factors on outcome of root canal treatment.
}

\section{Laukkanen, Erika}

2019-10-01

Laukkanen , E , Vehkalahti, M M \& Kotiranta , A 2019 , ' Impact of systemic diseases and tooth-based factors on outcome of root canal treatment. ' , International Endodontic Journal , pÿvol. 52 , no. 10 , pp. 14171426 . https://doi.org/10.1111/iej.13143

http://hdl.handle.net/10138/312928

https://doi.org/10.1111/iej.13143

acceptedVersion

Downloaded from Helda, University of Helsinki institutional repository.

This is an electronic reprint of the original article.

This reprint may differ from the original in pagination and typographic detail.

Please cite the original version. 
MRS. ERIKA LAUKKANEN (Orcid ID : 0000-0001-8968-2981)

DR. MIIRA M VEHKALAHTI (Orcid ID : 0000-0002-6319-854X)

Article type : Original Scientific Article

Impact of systemic diseases and tooth-based factors on outcome of root canal treatment

E. Laukkanen ${ }^{1,2,3}$, M. M. Vehkalahti ${ }^{1}$, A. K. Kotiranta ${ }^{1,2,3}$

${ }^{1}$ Department of Oral and Maxillofacial Diseases, University of Helsinki, ${ }^{2}$ Oral Health Care, Department of Social Services and Health Care, City of Helsinki, ${ }^{3}$ Department of Oral and Maxillofacial Diseases, Helsinki University Hospital, Helsinki, Finland

Running title: Health status and endodontics

Keywords: Cardiovascular disease; Diabetes; Endodontic; Outcome; Root canal treatment; Tooth type

\section{Corresponding author:}

Erika Laukkanen

Department of Oral and Maxillofacial Diseases, University of Helsinki, P.O. Box 41, FI-00014

University of Helsinki, Finland

E-mail: erika.laukkanen@fimnet.fi

Phone: $+358-407286640$

This article has been accepted for publication and undergone full peer review but has not been through the copyediting, typesetting, pagination and proofreading process, which may lead to differences between this version and the Version of Record. Please cite this article as doi: 10.1111/iej.13143

This article is protected by copyright. All rights reserved. 


\section{Abstract}

Aim To investigate the impact of systemic health and tooth-based factors on the outcome of root canal treatment $(\mathrm{RCT})$.

Methodology The target population consisted of all patients receiving non-surgical RCT at the Helsinki University Clinic in 2008-2011. The inclusion criteria were: diagnosable pre- and postoperative (minimum six months after root filling) radiographs and adequate patient records of RCT available. Teeth extracted for non-endodontic reasons were excluded. Patient documents including digital radiographs of 640 permanent teeth in 504 patients were scrutinized. The radiographs were assessed by two examiners under standardized conditions. The Periapical Index (PAI) was used to define radiographically "healthy" and "healing" cases as successful. Data included systemic health, technical quality of root fillings, type of restoration and level of alveolar bone loss. Statistical evaluation of differences between groups included Chi-squared tests and Fisher's exact tests. Logistic regression modelling utilizing robust standard errors to allow for clustering within patients was applied to analyze factors related to the outcome of RCT.

Results Patients' mean age was 51.5 years (standard deviation (SD) 15.0; range 10-83, 49\% were female. In 41 cases (6\%), the patient had diabetes mellitus (DM), in 132 (21\%) cardiovascular disease and in 284 (44\%) no systemic disease. The follow-up period was 6-71 months (mean 22.7). In the primary analyses, the success rate of RCT was $73.2 \%$ in DM patients and $85.6 \%$ in patients with no systemic disease $(P=0.043)$; other systemic diseases had no impact on success. In the multifactorial analysis, the impact of DM became non-significant and RCTs were more likely to succeed in the absence of apical periodontitis (AP) (odds ratio $(\mathrm{OR})=4.4 ; P<0.001$ ), in teeth with optimal root filling quality ( $O R=2.5 ; P<0.001)$, in teeth restored with indirect restorations ( $O R=3.7 ; P=0.002)$ and in teeth with none/mild alveolar bone loss (OR 2.4; $P=0.003$ ).

This article is protected by copyright. All rights reserved. 
Conclusions DM diminished the success of RCT, especially in teeth with apical periodontitis. However, tooth-based factors had a more profound impact on the outcome of RCT. This should be considered in clinical decision-making and in assessment of root canal treatment prognosis.

\section{Introduction}

The systemic health status of a patient may influence the outcome of root canal treatment (RCT) (Segura-Egea et al. 2016, Aminoshariae et al. 2017, Cabanillas-Balsera et al. 2018), but thus far the evidence is scarce. The main groups of systemic diseases of interest are diabetes mellitus (DM) and cardiovascular disease (CVD), which are notably prevalent and therefore important in relation to oral infections.

Marginal periodontitis and apical periodontitis (AP) are both chronic oral infections that share essential features: polymicrobial pathogenesis with predominance of anaerobic bacteria and inflammatory host response with locally and systemically elevated cytokine levels (Caplan et al. 2006). Marginal periodontitis is associated with systemic health disorders such as DM (Polak \& Shapira 2018) and CVD (Lockhart et al. 2012). Based on similar mechanisms of disease, an association between AP and systemic diseases may exist.

DM is an immunosuppressive condition and may therefore act as a disease modifier in AP. Some studies suggest that DM patients have AP more often than non-DM patients (López-López et al. 2011, Segura-Egea et al. 2012, 2016, Tibúrcio-Machado et al. 2017), although there are some contradictory findings (Sánchez-Domínguez et al. 2015). RCTs may also be more common (LópezLópez et al. 2011) and the outcome of RCT poorer (Aminoshariae et al. 2017) in DM patients. However, the evidence remains inconclusive.

This article is protected by copyright. All rights reserved. 
An association between CVD and AP is suggested by two recent systematic reviews (Khalighinejad et al. 2016, Berlin-Broner et al. 2017). The relationship between CVD and outcome of RCT has rarely been studied and the results are controversial (Mindiola et al. 2006, Wang et al. 2011, Ng et al. 2011).

Previous studies investigating systemic diseases in relation to endodontic outcome have mainly focused on survival of the tooth, not periapical healing. In addition, these studies have rarely analysed other simultaneous factors known to affect outcome. Therefore, the aim of this retrospective study was to investigate the outcome (periapical healing) of RCT in relation to systemic diseases and tooth-based factors.

\section{Material and Methods}

\section{Ethical considerations}

This study was approved by the Department of Social Services and Health Care of the City of Helsinki (HEL 2012-012378). Data are based on electronic patient records and radiographs and stored in a database using running numbers as patient identification.

\section{Setting and cases}

All RCTs were performed by $4^{\text {th }}$ and $5^{\text {th }}$ year dental students under strict supervision by qualified endodontists. Dental students at the University of Helsinki performed their clinical training at Helsinki University Clinic as part of the public oral health service of the City of Helsinki. Since 2001, these services have been open to all citizens. The patients receiving RCT were either admitted for comprehensive dental care by making an appointment themselves or upon referral for RCT by dentists working in other units of public services. RCT followed a strict protocol emphasizing aseptic control.

This article is protected by copyright. All rights reserved. 
Patients who underwent RCT at Helsinki University Clinic between 2008 and 2011 formed the target population. The inclusion criteria were as follows: a follow-up radiograph taken a minimum of 6 months after root canal filling, pre- and post-operative radiographs available, adequate patient records of the RCT available, no fractured instrument existing in the canals preoperatively and no endodontic surgery pre-planned for the case. Teeth extracted for non-endodontic reasons were excluded.

\section{Data recordings}

Data collected from patient documents included systemic health information reported by the patient. Patients were categorized by systemic health to those with DM, other immunosuppressive conditions (autoimmune disease, cancer, immunosuppressive medication), CVD, any other systemic diseases and no systemic diseases. In case the patient had more than one systemic condition, he/she was categorized to the group first appearing in the list above. For instance, a patient with both DM and CVD was allocated the group of DM patients.

The type of tooth was recorded as molars or non-molars (incisors, canines and premolars) and treatment modality as primary (first-time) or secondary (retreatment) RCT. Further, preoperative periapical status was recorded as AP or no apical periodontitis (NAP). Alveolar bone loss was recorded as none/mild (none or up to the coronal third of the root) or severe (up to the middle or apical third of the root). The type of restoration was recorded as direct or indirect (cuspal coverage including crowns). Root filling length was recorded as flush (0-2 mm from apex), short (>2 $\mathrm{mm}$ from apex) or overfilled. Possible overextension of root canal sealer was not recorded as overfilling. Root filling density was evaluated separately for each third of the root and for all roots in multi-rooted teeth and recorded as optimal or suboptimal (European Society of Endodontology 2006). The technical quality of the root filling was recorded as optimal when the root filling length was flush and the density of the root filling was optimal in all parts of the root(s), otherwise it was recorded as suboptimal. Patient details, gender and age in years, were recorded.

This article is protected by copyright. All rights reserved. 


\section{Clinical protocol}

The clinical protocol followed ESE guidelines (European Society of Endodontology 2006). Before RCT a preoperative radiograph was taken and the tooth assessed in terms of restorability, periodontal status and relevance in occlusion. The tooth was anaesthetized (when needed), and caries and defective restorations were removed. An access cavity was prepared, root canals localized, rubber dam placed and the working field disinfected with $0.5 \%$ chlorhexidine $+96 \%$ ethanol solution (Klorhexol ${ }^{\circledR}$; Takeda OY, Helsinki, Finland). Working length was determined using an electronic apex locator and confirmed with a radiograph when needed. Chemo-mechanical debridement was carried out with Nickel-Titanium (NiTi) hand files (K-files) and with rotary NiTi instruments (Profile ${ }^{\circledR}$; Dentsply Sirona, Inc., York, PA, USA) with minimum apical preparation to size $35, .04$ taper. For retreatment cases, the gutta-percha was removed using rotary instruments (R-endo ${ }^{\circledR}$; Micro-Mega ${ }^{\circledR}$ SA, Besançon, France, or Protaper ${ }^{\circledR}$ Universal D1-3; Dentsply Tulsa Dental Specialities, Johnson City, TN, USA) and chloroform, if needed. Copious amounts of $0.5-1.0 \%$ sodium hypochlorite were used for irrigation. At the end of the preparation, the smear layer was removed with $17 \%$ ethylenediaminetetraacetic acid (EDTA). Klorhexol $^{\circledR}$ (Takeda OY, Helsinki, Finland) was used for final irrigation.

Most RCTs (94\%), including treatments of teeth with vital pulps, were carried out over multiple visits for scheduling reasons. Between visits the root canals were dressed with calcium hydroxide paste (Ultracal ${ }^{\circledR}$ XS; Ultradent Products Inc., South Jordan, UT, USA). A master cone radiograph was taken before the root filling. The root canals were filled using the cold lateral condensation technique with gutta-percha and sealer (AH Plus ${ }^{\circledR}$; Dentsply Sirona, Inc., York, PA, USA), and a post-operative radiograph was taken. The tooth was either restored during the same visit or temporized with two layers of temporary filling material (Cavit ${ }^{\mathrm{TM}}-\mathrm{G} ; 3 \mathrm{M}^{\mathrm{TM}}$, St. Paul, MN, USA and IRM ${ }^{\circledR}$; Dentsply Caulk, Milford, DE, USA or Cavit ${ }^{\mathrm{TM}}-\mathrm{G}$ and resin-modified glass ionomer) until final restoration.

This article is protected by copyright. All rights reserved. 


\section{Assessment of radiographs}

All radiographs were digital. Most images were intraoral periapical radiographs. In some cases, if a panoramic radiograph was available and diagnosable, it was used in addition or solely ( $9 \%$ of cases) for assessment of follow-up periapical status. The technical quality of a root filling was assessed from a periapical radiograph in all cases. Periapical radiographs were taken using a beam-guiding device and the paralleling technique. The radiographs were assessed separately from clinical information, in a room with dimmed lights and a high-quality computer screen (EIZO ${ }^{\circledR}$ Radiforce MX220W; EIZO Corporation, Ishikawa, Japan). Periapical status was defined using the Periapical Index (PAI), a five-step scoring system with each step representing a shift from healthy periapical tissues to severe AP (Ørstavik et al. 1986). Calibration of the two examiners (a qualified endodontist, A.K., and an endodontics postgraduate student, E.L.) included observation of a set of 50 radiographs. Written instructions and reference radiographs were available while examining the radiographs. For multi-rooted teeth, a PAI score was assigned to each root, but recorded by tooth as the greatest score of the roots. If in doubt between scores, the greater PAI score was chosen. The two examiners evaluated the radiographs by discussing them to reach consensus. In addition, an oral and maxillofacial radiologist was consulted about radiographs of maxillary molars because of their complex anatomy and position.

\section{Outcome was recorded as follows:}

1. Healthy: Healthy periapical tissues (PAI score 1-2).

2. Healing: Apical radiolucency considerably smaller in follow-up radiograph than in preoperative radiograph.

3. No healing:

a) Periapical radiolucency remained the same (PAI score 3-5).

b) Teeth extracted for endodontic reasons (persisting apical infection, fistula) or for reasons not recorded in documents available after root filling.

This article is protected by copyright. All rights reserved. 

c) Teeth receiving periapical surgery.
d) Periapical radiolucency not completely disappeared after 4 years.

4. Deteriorated: Periapical radiolucency enlarged or a new periapical radiolucency emerged (PAI score 3-5).

The outcome was then dichotomized as successful (healthy and healing) or unsuccessful (no healing and deteriorated). Success rate (SR) was defined as percentage of cases with successful outcome.

\section{Statistical analysis}

To evaluate differences between the groups, we used Chi-squared tests and Fisher's exact tests for frequencies. $P$-values below 0.05 were considered to be statistically significant. Further, factors related to outcome were analysed by applying logistic regression modelling and calculating odds ratios (ORs) and their $95 \%$ confidence intervals ( $95 \% \mathrm{Cls}$ ) using robust standard error to adjust for clustering effects of several teeth within patients. The Hosmer and Lemeshow test was used to assess goodness of fit for the models. Statistical analyses were performed using IBM ${ }^{\circ}$ SPSS $₫$ Statistics version 25 and Stata ${ }^{\circledR} /$ MP version 15.1 (StataCorp, College Station, TX, USA).

\section{Results}

\section{Characteristics of cases}

Altogether 640 permanent teeth in 504 patients were analysed: 281 molars (43.9\%) and 359 nonmolars (56.1\%). The follow-up period was 6-71 months (mean 22.7 months); only the latest followup was included for each tooth. In 41 cases (6.4\%), the patient had DM and in $132(20.6 \%)$ the patient had CVD. In 284 cases (44.4\%), the patient had no systemic disease. According to systemic diseases, the groups had no difference in preoperative periapical status, type of tooth, technical quality of root filling, type of restoration, alveolar bone loss or the length of follow-up $(P>0.05)$. The quality of root filling was optimal in 152 molars $(54.1 \%)$ and in 278 non-molars $(77.4 \%)(P<0.001)$. 
The overall success rate was $84.1 \% ; 79.7 \%$ for molars and $87.5 \%$ for non-molars $(P=0.008)$. The characteristics of patients and root filled teeth are presented in Table 1.

\section{Outcome and systemic health}

The success rate of RCT in patients with no systemic diseases was $85.6 \%$. Compared with healthy individuals, patients with DM and patients with other immunosuppression had success rates of 73.2\% $(P=0.043)$ and 78.6\% $(P=0.241)$, respectively. Patients with DM were the only group with a significant difference in success rate of RCT relative to patients with no systemic disease (Table 2).

The overall success rate for teeth with AP preoperatively was $77.3 \%$ and for teeth without AP $94.5 \%$ $(P<0.001)$. In DM patients, the corresponding figures were $56 \%$ and $100 \%(P=0.003)$. CVD patients had success rates of $81.3 \%$ and $98.1 \%(P=0.008)$ for teeth with and without preoperative AP, respectively (Table 3 , Figure 1 ).

The success rate was greater for teeth with optimal quality root fillings than for teeth with suboptimal quality root fillings; $88.4 \%$ vs. $75.2 \%(P<0.001)$, and for teeth with indirect cuspal coverage restorations than for teeth with direct restorations, $95.2 \%$ vs. $81.5 \%(P<0.001)$. Although all of the tooth-based factors, i.e. preoperative periapical status, quality of root filling, type of restoration, type of tooth and level of alveolar bone loss, significantly impacted the overall success of RCT (Table 3), the impact varied according to systemic diseases. In DM patients, the only toothbased factor influencing outcome was preoperative periapical status.

Table 4 presents logistic regression modelling for simultaneously assessing the outcome of RCT according to DM, preoperative periapical status, type of restoration, quality of root filling, level of alveolar bone loss and type of tooth. Success was more likely for NAP teeth than for AP teeth (OR = $4.4 ; 95 \% \mathrm{Cl}=2.4-8.2)$, for teeth with optimal rather than suboptimal quality root fillings $(\mathrm{OR}=2.5$;

This article is protected by copyright. All rights reserved. 
$95 \% \mathrm{Cl}=1.5-4.2)$, for teeth restored with indirect rather than direct fillings (OR $=3.7 ; 95 \% \mathrm{Cl} 1.7-8.4)$ and for teeth with none/mild rather than severe alveolar bone loss (OR $=2.4 ; 95 \% \mathrm{Cl} 1.4-4.4)$. In this model, the impact of DM and type of tooth on the outcome of RCT remained non-significant.

\section{Discussion}

This study investigated the impact of systemic diseases and tooth-based factors on the outcome of RCT. The success of RCT was poorest in DM patients. Other systemic diseases had no impact on outcome. In the multifactorial analysis, preoperative AP, suboptimal root filling quality, direct filling, and severe alveolar bone loss of the RCT tooth had a negative impact on the success of RCT.

This practice-based study had a representative material, as the RCTs investigated were carried out in the public health care system, open to all citizens. RCTs were performed by dental students under strict supervision, and a standardized treatment protocol was applied. Previous studies investigating systemic diseases in relation to endodontic outcome have mainly focused on survival of the tooth, not periapical healing. The present study examined the outcome of RCT in terms of periapical healing. The wide range of material allowed analyses of the impact of various systemic diseases and tooth-based factors on the outcome.

Integrity of the non-specific immune system can be assumed to be a significant predictor for root canal treatment outcome (Marending et al. 2005). In patients with deficient immune systems, the healing process after RCT might be hindered by residual infection or inflammation in the periapical tissue, while in healthy individuals the residual infection would be controlled by the host's immune system (Wang et al. 2011). In the present study, patients were divided into groups based on systemic diseases that may alter the healing process. The systemic health information was based on self-reported medical history and collected from patient documents and might therefore be imperfect. The severity of immunosuppression likely varies between different conditions and 
individuals. However, no laboratory test results, such as glycaemic control or white blood cell count, were available, and therefore, the severity of the immunosuppression could not be established on an individual basis.

Healing of periapical pathosis might be slower in patients with immunosuppressive conditions such as DM (Arya et al. 2017). As the follow-up period varied from 6 to 71 months, both radiographically "healed" and "healing" cases were categorized as successful. This approach minimizes the possible distortion of results by slower healing in patients with deficient immune systems.

Systemic diseases and oral infections share many risk factors such as tobacco smoking. This was a patient document-based study, and at the time of the investigation the documentation of smoking was not systematic. Therefore, smoking was not recorded. Smoking might act as a confounding factor, although evidence of the effect of smoking on periapical healing is contradictory (Doyle et al. 2007, Azim et al. 2016).

The presence of AP prior to RCT has been shown to be the single most prominent factor worsening the outcome of RCT (Ng et al. 2008). Also tooth-based factors, such as the technical quality of the root filling, affect the outcome (Ng et al. 2008). However, earlier studies investigating the impact of systemic diseases on the outcome of RCT have seldom analysed these factors simultaneously. This deficiency was also pointed out in recent systematic reviews of the association of systemic diseases with endodontic outcome (Aminoshariae et al. 2017, Cabanillas-Balsera et al. 2018). The comprehensive material in the present study, however, allowed these tooth-based factors to be included and stratified in the analyses. The clustering effect of several teeth within patient was controlled by the use of robust standard errors in the multifactorial model. This, however, had only minor impact on the results, because of the vast amount of clusters (640 teeth in 504 patients). The ORs for success in the model have been reported, but dichotomies of the dependent variable and all 
the covariates allows the ORs to be construed for failure as well by switching the reference group within covariate.

In the primary analyses, the outcome of RCT was poorer in DM patients, especially in the presence of AP preoperatively. Earlier studies have rarely stratified the analyses by AP, but Fouad \& Burleson (2003) reported the outcome of RCT to be poorer in AP teeth of DM patients. However, the same study found no difference in outcome when teeth without preoperative AP were included (Fouad \& Burleson 2003). A prospective study of 60 mandibular molars with preoperative AP found healing to be delayed but not compromised in DM patients (Arya et al. 2017). A retrospective study (Azim et al. 2016) divided patients into a 'compromised healing' group, including patients with DM, HIV/AIDS, cancer/chemotherapy, hepatitis ( $\mathrm{B}$ or $\mathrm{C}$ ), autoimmune disease, anaemia and patients taking bisphosphonates or immunosuppressive drugs, and a 'non-compromised healing' group, including healthy patients and patients with medical conditions other than those listed above, and found healing to be slower in the 'compromised healing' group. Also, when the endodontic outcome of interest has been the survival of the tooth, not periapical healing, DM patients have been associated with poorer outcomes than healthy subjects (Mindiola et al. 2006, Wang et al. 2011, Ng et al. 2011). The present results in the multifactorial analysis revealed preoperative AP, quality of root filling, type of restoration, and level of alveolar bone loss to be significant factors influencing the outcome of RCT; the impact of DM remained non-significant.

There are similar inflammatory mediators involved in both CVD and AP (Cotti et al. 2011, Gomes et al. 2013, Hernández-Ríos et al. 2017), and AP may contribute to systemic inflammatory burden (Gomes et al. 2013). It has been suggested that AP may be associated with CVDs in a similar manner as periodontal disease (Khalighinejad et al. 2016). The impaired immune response associated with systemic disease together with the pro-inflammatory status may affect periapical healing (SeguraEgea et al. 2015). A Finnish study found AP to be an independent risk factor for incident

This article is protected by copyright. All rights reserved. 
cardiovascular events (Liljestrand et al. 2016). The same study postulated that endodontic treatment might attenuate the association between AP and coronary artery disease. All CVD diagnoses (hypertension, coronary artery disease, valvular heart disease) were analysed together and no difference was found in the outcome of RCT between CVD patients and healthy subjects. Previous studies investigating CVD and endodontic outcome have focused on the survival of RCT teeth only (Mindiola et al. 2006, Wang et al. 2011, Ng et al. 2011), ignoring periapical healing, and therefore, cannot be compared with the present findings. The results of these earlier studies are controversial, as two papers described the survival to be poorer in CVD patients (Mindiola et al. 2006, Wang et al. 2011), but one paper found no such difference (Ng et al. 2011).

The technical quality of a root filling reflects the overall quality of the RCT. The success of RCT was poorer in teeth with suboptimal root filling quality, similarly to many previous studies (Sjögren et al. 1990, Farzaneh et al. 2004, Azim et al. 2016). Moreover, cross-sectional studies have shown AP to exist more often in root filled teeth with poor quality root fillings than in teeth with good quality root fillings (De Moor et al. 2000, Ridell et al. 2006, Tavares et al. 2009, Huumonen et al. 2017).

Coronal leakage is a risk factor for re-infection of the root canal system after RCT, especially over time. In fact, the significance of good quality restorations is equivalent to the significance of good quality root fillings in the success of RCT (Gillen et al. 2011). In this study, the quality of restorations was not evaluated, which can be considered a limitation of the study. Periapical healing of teeth restored with indirect cuspal-coverage restorations (including crowns) were compared with direct fillings and the success of RCT was greater for teeth with indirect restorations. Results of previous studies examining the impact of type of restoration on periapical healing are inconsistent (Lee et al. 2012, Fransson et al. 2016, Dawson et al. 2016). By contrast, studies investigating the survival of root filled teeth have reported indirect restorations to enhance survival (Cheung \& Chan 2003, Fransson et al. 2016).

This article is protected by copyright. All rights reserved. 
One of the main reasons for tooth extraction after RCT is periodontal disease ( $\mathrm{Ng}$ et al. 2010). A recent meta-analysis suggested that future studies on the success of RCT in DM patients should control the confounding effect of periodontal disease (Cabanillas-Balsera et al. 2018). In the present study teeth extracted for periodontal reasons were excluded from the analyses. However, severe alveolar bone loss of the RCT tooth diminished the success of RCT in the primary analyses as well as in the multifactorial model. In previous studies, marginal support of the RCT tooth has been shown to impact on periapical healing ( $\varnothing$ rstavik et al. 2004) and also the survival of the root filled tooth (Khalighinejad et al. 2017).

Further longitudinal studies are needed to evaluate the effect of systemic diseases on periapical healing and also the impact of root canal treatment on systemic diseases. The possible association of endodontic disease with glycaemic control of DM or risk of developing CVD highlights the importance of root canal treatment and proper follow-up of root filled teeth.

\section{Conclusion}

The outcome of RCT might be poorer in DM patients, especially in AP teeth. In this study, other systemic diseases had no impact on the outcome of RCT. Tooth-based factors: preoperative AP, suboptimal root filling quality, direct filling, and severe alveolar bone loss of the RCT tooth were verified as significant factors diminishing the success of RCT in a multifactorial model. These findings should be considered in clinical decision-making and in assessment of RCT prognosis.

\section{Conflict of Interest statement}

Mrs Laukkanen reports grants from the Finnish Dental Society Apollonia, the Finnish Association for Dentists in Public Health Care, the Finnish Association for Women Dentists and the City of Helsinki [grant number HEL 2017-004388] during the conduct of the study. The other authors have stated explicitly that there are no conflicts of interest in connection with this article.

This article is protected by copyright. All rights reserved. 


\section{References}

Aminoshariae A, Kulild JC, Mickel A, Fouad AF (2017) Association between Systemic Diseases and Endodontic Outcome: A Systematic Review. Journal of Endodontics 43, 514-9.

Arya S, Duhan J, Tewari S, Sangwan P, Ghalaut V, Aggarwal S (2017) Healing of Apical Periodontitis after Nonsurgical Treatment in Patients with Type 2 Diabetes. Journal of Endododontics 43, 1623-7. Azim AA, Griggs JA, Huang GT (2016) The Tennessee study: factors affecting treatment outcome and healing time following nonsurgical root canal treatment. International Endodontic Journal 49, 6-16. Berlin-Broner Y, Febbraio M, Levin L (2017) Association between apical periodontitis and cardiovascular diseases: a systematic review of the literature. International Endodontic Journal 50, 847-59.

Cabanillas-Balsera D, Martín-González J, Montero-Miralles P, Sánchez-Domínguez B, JiménezSánchez MC, Segura-Egea JJ (2018) Association between diabetes and nonretention of root filled teeth: a systematic review and meta-analysis. International Endodontic Journal 52, 297-306.

Caplan DJ, Chasen JB, Krall EA et al. (2006) Lesions of endodontic origin and risk of coronary heart disease. Journal of Dental Research 85, 996-1000.

Cheung GS, Chan TK (2003) Long-term survival of primary root canal treatment carried out in a dental teaching hospital. International Endodontic Journal 36, 117-28.

Cotti E, Dessì C, Piras A et al. (2011) Association of endodontic infection with detection of an initial lesion to the cardiovascular system. Journal of Endodontics 37, 1624-9.

Dawson VS, Petersson K, Wolf E, Akerman S (2016) Periapical Status of Root-filled Teeth Restored with Composite, Amalgam, or Full Crown Restorations: A Cross-sectional Study of a Swedish Adult Population. Journal of Endodontics 42, 1326-33.

De Moor RJ, Hommez GM, De Boever JG, Delmé KI, Martens GE (2000) Periapical health related to the quality of root canal treatment in a Belgian population. International Endodontic Journal 33, 11320.

This article is protected by copyright. All rights reserved. 
Doyle SL, Hodges JS, Pesun IJ, Baisden MK, Bowles WR (2007) Factors affecting outcomes for singletooth implants and endodontic restorations. Journal of Endododontics 33, 399-402.

European Society of Endodontology (2006) Quality guidelines for endodontic treatment: consensus report of the European Society of Endodontology. International Endodontic Journal 39, 921-30. Farzaneh M, Abitbol S, Lawrence H, Friedman S (2004) Treatment Outcome in Endodontics-The Toronto Study. Phase II: Initial Treatment. Journal of Endodontics 30, 302-9.

Fouad AF, Burleson J (2003) The effect of diabetes mellitus on endodontic treatment outcome: data from an electronic patient record. Journal of American Dental Association 134, 43-51; quiz 117-8. Fransson H, Dawson VS, Frisk F, Bjørndal L, EndoReCo, Kvist T (2016) Survival of Root-filled Teeth in the Swedish Adult Population. Journal of Endodontics 42, 216-20.

Gillen BM, Looney SW, Gu LS et al. (2011) Impact of the quality of coronal restoration versus the quality of root canal fillings on success of root canal treatment: a systematic review and metaanalysis. Journal of Endodontics 37, 895-902.

Gomes MS, Blattner TC, Sant'Ana Filho M et al. (2013) Can apical periodontitis modify systemic levels of inflammatory markers? A systematic review and meta-analysis. Journal of Endodontics 39, 1205-17.

Hernández-Ríos P, Pussinen PJ, Vernal R, Hernández M (2017) Oxidative Stress in the Local and Systemic Events of Apical Periodontitis. Frontiers in Physiology 8, 869.

Huumonen S, Suominen AL, Vehkalahti MM (2017) Prevalence of apical periodontitis in root filled teeth: findings from a nationwide survey in Finland. International Endodontic Journal 50, 229-36. Khalighinejad N, Aminoshariae A, Kulild JC, Wang J, Mickel A (2017) The Influence of Periodontal Status on Endodontically Treated Teeth: 9-year Survival Analysis. Journal of Endodontics 43, 1781-5. Khalighinejad N, Aminoshariae MR, Aminoshariae A, Kulild JC, Mickel A, Fouad AF (2016) Association between Systemic Diseases and Apical Periodontitis. Journal of Endodontics 42, 1427-34. Lee AH, Cheung GS, Wong MC (2012) Long-term outcome of primary non-surgical root canal treatment. Clinical Oral Investigations 16, 1607-17.

This article is protected by copyright. All rights reserved. 
Liljestrand JM, Mäntylä P, Paju S et al. (2016) Association of Endodontic Lesions with Coronary Artery Disease. Journal of Dental Research 95, 1358-65.

Lockhart PB, Bolger AF, Papapanou PN et al. (2012) Periodontal disease and atherosclerotic vascular disease: does the evidence support an independent association?: a scientific statement from the American Heart Association. Circulation 125, 2520-44.

López-López J, Jané-Salas E, Estrugo-Devesa A, Velasco-Ortega E, Martín-González J, Segura-Egea JJ (2011) Periapical and endodontic status of type 2 diabetic patients in Catalonia, Spain: a crosssectional study. Journal of Endodontics 37, 598-601.

Marending M, Peters OA, Zehnder M (2005) Factors affecting the outcome of orthograde root canal therapy in a general dentistry hospital practice. Oral Surgery, Oral Medicine, Oral Pathology, Oral Radiology, and Endodontology 99, 119-24.

Mindiola MJ, Mickel AK, Sami C, Jones JJ, Lalumandier JA, Nelson SS (2006) Endodontic treatment in an American Indian population: a 10-year retrospective study. Journal of Endodontics 32, 828-32.

Ng YL, Mann V, Gulabivala K (2010) Tooth survival following non-surgical root canal treatment: a systematic review of the literature. International Endodontic Journal 43, 171-89.

Ng YL, Mann V, Gulabivala K (2011) A prospective study of the factors affecting outcomes of nonsurgical root canal treatment: part 2: tooth survival. International Endodontic Journal 44, 610-25. Ng YL, Mann V, Rahbaran S, Lewsey J, Gulabivala K (2008) Outcome of primary root canal treatment: systematic review of the literature -- Part 2. Influence of clinical factors. International Endodontic Journal 41, 6-31.

Polak D, Shapira L (2018) An update on the evidence for pathogenic mechanisms that may link periodontitis and diabetes. Journal of Clinical Periodontology 45, 150-66.

Ridell K, Petersson A, Matsson L, Mejàre I (2006) Periapical status and technical quality of root-filled teeth in Swedish adolescents and young adults. A retrospective study. Acta Odontologica Scandinavica 64, 104-10.

This article is protected by copyright. All rights reserved. 
Sánchez-Domínguez B, López-López J, Jané-Salas E, Castellanos-Cosano L, Velasco-Ortega E, SeguraEgea JJ (2015) Glycated hemoglobin levels and prevalence of apical periodontitis in type 2 diabetic patients. Journal of Endodontics 41, 601-6.

Segura-Egea JJ, Castellanos-Cosano L, Machuca G et al. (2012) Diabetes mellitus, periapical inflammation and endodontic treatment outcome. Medicina Oral Patología Oral y Cirugia Bucal, e356-e61.

Segura-Egea JJ, Martín-González J, Cabanillas-Balsera D, Fouad AF, Velasco-Ortega E, López-López J (2016) Association between diabetes and the prevalence of radiolucent periapical lesions in rootfilled teeth: systematic review and meta-analysis. Clinical Oral Investigations 20, 1133-41. Segura-Egea JJ, Martín-González J, Castellanos-Cosano L (2015) Endodontic medicine: connections between apical periodontitis and systemic diseases. International Endodontic Journal 48, 933-51. Sjögren U, Hägglund B, Sundqvist G, Wing K (1990) Factors affecting the long-term results of endodontic treatment. Journal of Endodontics 16, 498-504.

Tavares PB, Bonte E, Boukpessi T, Siqueira JF, Jr., Lasfargues JJ (2009) Prevalence of apical periodontitis in root canal-treated teeth from an urban French population: influence of the quality of root canal fillings and coronal restorations. Journal of Endodontics 35, 810-3.

Tibúrcio-Machado CD, Bello MC, Maier J, Wolle CF, Bier CA (2017) Influence of Diabetes in the Development of Apical Periodontitis: A Critical Literature Review of Human Studies. Journal of Endodontics 43, 370-6.

Wang CH, Chueh LH, Chen SC, Feng YC, Hsiao CK, Chiang CP (2011) Impact of diabetes mellitus, hypertension, and coronary artery disease on tooth extraction after nonsurgical endodontic treatment. Journal of Endodontics 37, 1-5.

Ørstavik D, Kerekes K, Eriksen HM (1986) The periapical index: a scoring system for radiographic assessment of apical periodontitis. Endodontics \& Dental Traumatology 2, 20-34.

$\emptyset$ rstavik D, Qvist V, Stoltze K (2004) A multivariate analysis of the outcome of endodontic treatment. European Journal of Oral Sciences 112, 224-30.

This article is protected by copyright. All rights reserved. 
Table 1 Systemic health status of patients and characteristics of root canal treatment (RCT) teeth ( $n=640)$ according to type of tooth. $P$-values refer to differences between non-molars and molars.

\begin{tabular}{|c|c|c|c|c|}
\hline Characteristic & $\begin{array}{c}\text { All } \\
N=640 \\
n(\%)\end{array}$ & $\begin{array}{c}\text { Non-molars } \\
n=359 \\
n(\%)\end{array}$ & $\begin{array}{c}\text { Molars } \\
n=281 \\
n(\%)\end{array}$ & $P$-value \\
\hline \multicolumn{5}{|l|}{ Systemic diseases } \\
\hline Diabetes mellitus & $41(6.4)$ & $23(6.4)$ & $18(6.4)$ & 0.080 \\
\hline Other immunosuppression & $42(6.6)$ & $26(7.2)$ & $16(5.7)$ & \\
\hline Cardiovascular diseases & $132(20.6)$ & $86(24.0)$ & $46(16.4)$ & \\
\hline Other systemic diseases & $141(22.0)$ & $80(22.3)$ & $61(21.7)$ & \\
\hline No systemic diseases & $284(44.4)$ & $144(40.1)$ & $140(49.8)$ & \\
\hline \multicolumn{5}{|l|}{ Level of alveolar bone loss } \\
\hline None & $291(45.5)$ & $145(40.4)$ & $146(52.0)$ & 0.011 \\
\hline Mild & $259(40.5)$ & $156(43.5)$ & $103(36.7)$ & \\
\hline Severe & $90(14.1)$ & $58(16.2)$ & $32(11.4)$ & \\
\hline \multicolumn{5}{|l|}{ Root filling length } \\
\hline Flush (0-2mm from apex) & $490(76.6)$ & $309(86.1)$ & $181(64.4)$ & $<0.001$ \\
\hline Short (>2mm from apex) & $112(17.5)$ & $34(9.5)$ & $78(27.8)$ & \\
\hline Overfilled & $38(5.9)$ & $16(4.5)$ & $22(7.8)$ & \\
\hline \multicolumn{5}{|l|}{ Root filling density } \\
\hline Optimal & $544(85.0)$ & $323(90.0)$ & $221(78.6)$ & $<0.001$ \\
\hline Suboptimal & $96(15.0)$ & $36(10.0)$ & $60(21.4)$ & \\
\hline \multicolumn{5}{|l|}{ Root filling quality } \\
\hline Optimal & $430(67.2)$ & $278(77.4)$ & $152(54.1)$ & $<0.001$ \\
\hline Suboptimal & $210(32.8)$ & $81(22.6)$ & $129(45.9)$ & \\
\hline \multicolumn{5}{|l|}{ Type of restoration } \\
\hline Direct & $509(80.2)$ & $281(78.9)$ & $228(81.7)$ & 0.382 \\
\hline Indirect & $126(19.8)$ & $75(21.1)$ & $51(18.3)$ & \\
\hline Data missing $(n=5)$ & 5 & 3 & 2 & \\
\hline \multicolumn{5}{|l|}{ Preoperative periapical status } \\
\hline No apical periodontitis (NAP) & $253(39.5)$ & $145(40.4)$ & $108(38.4)$ & 0.616 \\
\hline Apical periodontitis (AP) & $387(60.5)$ & $214(55.3)$ & $173(44.7)$ & \\
\hline \multicolumn{5}{|l|}{ Outcome of RCT } \\
\hline Success & $538(84.1)$ & 314 (87.5) & 224 (79.7) & 0.008 \\
\hline Failure & $102(15.9)$ & $45(12.5)$ & $57(20.3)$ & \\
\hline
\end{tabular}

Root filling quality: optimal = root filling length flush and root filling density optimal, otherwise suboptimal.

This article is protected by copyright. All rights reserved. 
Table 2 Success $^{\mathrm{a}}(\mathrm{n}(\%))$ of root canal treatment according to presence of systemic diseases.

\begin{tabular}{|c|c|c|c|}
\hline Systemic diseases & $\mathrm{n}$ (all) & Success, n (\%) & $P$-value \\
\hline Total & 640 & $538(84.1)$ & \\
\hline No systemic diseases (reference group) & 284 & $243(85.6)$ & \\
\hline DM & 41 & $30(73.2)$ & 0.043 \\
\hline Other immunosuppression & 42 & $33(78.6)$ & 0.241 \\
\hline CVD & 132 & 116 (87.9) & 0.523 \\
\hline Other systemic diseases & 141 & $116(82.3)$ & 0.377 \\
\hline \multicolumn{4}{|c|}{$\begin{array}{l}\text { a Success = Radiographic findings scored as "healthy" or "healing" at a minimum of } 6 \text { months of } \\
\text { follow-up. DM = Diabetes mellitus, CVD = Cardiovascular disease. Other immunosuppression = }\end{array}$} \\
\hline
\end{tabular}

This article is protected by copyright. All rights reserved. 
Table 3 Success as "healthy" or "healing" at a minimum of 6 months of follow-up (n/n, \%) of root canal treatments ( $n=640)$ by systemic diseases of the patient according to preoperative and treatment factors.

\begin{tabular}{|c|c|c|c|c|c|c|c|c|c|c|}
\hline \multirow[t]{2}{*}{ Systemic diseases } & \multicolumn{2}{|c|}{ Preoperative periapical status } & \multicolumn{2}{|c|}{ Quality of root filling } & \multicolumn{2}{|c|}{ Type of restoration $^{c}$} & \multicolumn{2}{|c|}{ Type of tooth } & \multicolumn{2}{|c|}{ Alveolar bone loss } \\
\hline & NAP & AP & Optimal & Sub-optimal & Direct & Indirect & Non-molar & Molar & None/Mild & Severe \\
\hline $\operatorname{DM}(n=41)$ & & & & & & & & & & \\
\hline Success $n / n$ & $16 / 16$ & $14 / 25$ & $20 / 25$ & $10 / 16$ & $22 / 31$ & $8 / 9$ & $18 / 23$ & $12 / 18$ & $22 / 28$ & $8 / 13$ \\
\hline success $\%$ & 100.0 & 56.0 & 80.0 & 62.5 & 71.0 & 88.9 & 78.3 & 66.7 & 78.6 & 61.5 \\
\hline$P$-value ${ }^{\text {a }}$ & \multicolumn{2}{|c|}{0.003} & \multicolumn{2}{|c|}{0.287} & \multicolumn{2}{|c|}{0.404} & \multicolumn{2}{|c|}{0.489} & \multicolumn{2}{|c|}{0.280} \\
\hline \multicolumn{11}{|l|}{$\begin{array}{l}\text { Other immuno- } \\
\text { suppression }(n=42)\end{array}$} \\
\hline Success $n / n$ & $16 / 17$ & $17 / 25$ & $24 / 27$ & $9 / 15$ & $21 / 27$ & $12 / 14$ & $22 / 26$ & $11 / 16$ & $29 / 33$ & $4 / 9$ \\
\hline success $\%$ & 94.1 & 68.0 & 88.9 & 60.0 & 77.8 & 85.7 & 84.6 & 68.8 & 87.9 & 44.4 \\
\hline$P$-value ${ }^{a}$ & \multicolumn{2}{|c|}{0.060} & \multicolumn{2}{|c|}{0.049} & \multicolumn{2}{|c|}{0.692} & \multicolumn{2}{|c|}{0.265} & \multicolumn{2}{|c|}{0.013} \\
\hline \multicolumn{11}{|l|}{ CVD (n=132) } \\
\hline Success $n / n$ & $51 / 52$ & $65 / 80$ & $85 / 94$ & $31 / 38$ & $93 / 109$ & $23 / 23$ & $77 / 86$ & $39 / 46$ & $96 / 110$ & $20 / 22$ \\
\hline success $\%$ & 98.1 & 81.3 & 90.4 & 81.6 & 85.3 & 100.0 & 89.5 & 84.8 & 87.3 & 90.9 \\
\hline$P$-value ${ }^{\mathrm{b}}$ & \multicolumn{2}{|c|}{0.004} & \multicolumn{2}{|c|}{0.159} & \multicolumn{2}{|c|}{0.050} & \multicolumn{2}{|c|}{0.425} & \multicolumn{2}{|c|}{0.633} \\
\hline \multicolumn{11}{|l|}{$\begin{array}{l}\text { Other systemic } \\
\text { diseases }(n=141)\end{array}$} \\
\hline Success $n / n$ & $54 / 61$ & $62 / 80$ & $82 / 96$ & $34 / 45$ & $90 / 114$ & $25 / 26$ & $67 / 80$ & $49 / 61$ & $103 / 122$ & $13 / 19$ \\
\hline success $\%$ & 88.5 & 77.5 & 85.4 & 75.6 & 78.9 & 96.2 & 83.8 & 80.3 & 84.4 & 68.4 \\
\hline$P$-value ${ }^{\mathrm{b}}$ & \multicolumn{2}{|c|}{0.089} & \multicolumn{2}{|c|}{0.153} & \multicolumn{2}{|c|}{0.039} & \multicolumn{2}{|c|}{0.598} & \multicolumn{2}{|c|}{0.089} \\
\hline \multicolumn{11}{|l|}{$\begin{array}{l}\text { No systemic } \\
\text { diseases }(n=284)\end{array}$} \\
\hline Success $n / n$ & $102 / 107$ & $141 / 177$ & $169 / 188$ & $74 / 96$ & $189 / 228$ & $52 / 54$ & $130 / 144$ & $113 / 140$ & $223 / 257$ & $20 / 27$ \\
\hline success $\%$ & 95.3 & 79.7 & 89.9 & 77.1 & 82.9 & 96.3 & 90.3 & 80.7 & 86.8 & 74.1 \\
\hline$P$-value ${ }^{\mathrm{b}}$ & \multicolumn{2}{|c|}{$<0.001$} & & & & & & & & \\
\hline Total $(n=640)$ & & & & & & & & & & \\
\hline Success $n / n$ & $239 / 253$ & $299 / 387$ & $380 / 430$ & $158 / 210$ & $415 / 509$ & $120 / 126$ & $314 / 359$ & $224 / 281$ & $473 / 550$ & $65 / 90$ \\
\hline success $\%$ & 94.5 & 77.3 & 88.4 & 75.2 & 81.5 & 95.2 & 87.5 & 79.7 & 87.9 & 72.2 \\
\hline$P$-value ${ }^{\mathrm{b}}$ & & & & & & & & & & \\
\hline
\end{tabular}

This article is protected by copyright. All rights reserved. 
$\mathrm{DM}=$ Diabetes mellitus, $\mathrm{CVD}=$ Cardiovascular disease, Other immunosuppression = Patients with autoimmune disease, cancer or immunosuppressive medication, NAP = no apical periodontitis, $\mathrm{AP}=$ apical periodontitis. Optimal root canal filling $=$ root filling length flush and root filling density optimal, otherwise suboptimal. Statistical evaluation by means of a. Fisher's exact tests or b. Chi-squared tests. c. Missing data for 5 cases.

This article is protected by copyright. All rights reserved. 
Table 4 Factors related to the success ${ }^{\mathrm{a}}$ of root canal treatment (RCT) by means of logistic regression modelling.

$\begin{array}{lllll}\text { Estimate } & \mathrm{SE}^{\mathrm{b}} & \mathrm{OR} & \mathbf{9 5 \%} \mathrm{Cl} & P \text {-value }\end{array}$

$\begin{array}{lccccc}\text { Diabetes mellitus (absent vs. present) } & 0.568 & 0.735 & 1.8 & 0.8-4.0 & 0.172 \\ \text { Preoperative periapical status } & 1.486 & 1.404 & 4.4 & 2.4-8.2 & <0.001 \\ \begin{array}{l}\text { (AP absent vs. present) } \\ \text { Type of restoration (indirect vs. direct) }\end{array} & 1.317 & 1.554 & 3.7 & 1.7-8.4 & 0.002 \\ \text { Quality of root filling (optimal vs. suboptimal) } & 0.919 & 0.657 & 2.5 & 1.5-4.2 & <0.001 \\ \text { Alveolar bone loss (none/mild vs. severe) } & 0.891 & 0.725 & 2.4 & 1.4-4.4 & 0.003 \\ \text { Type of tooth (non-molars vs. molars) } & 0.407 & 0.384 & 1.5 & 0.9-2.5 & 0.111\end{array}$

$\mathrm{HL}=0.807$

a. Success = Radiographic findings scored as "healthy" or "healing" at a minimum of 6 months of follow-up. b. SE = standard error estimated using robust standard error to adjust for clustering effect of several teeth within patient. $\mathrm{AP}=$ apical periodontitis, $\mathrm{OR}=$ odds ratio, $\mathrm{Cl}$ = confidence interval, $\mathrm{HL}=$ Hosmer and Lemeshow test for goodness of fit. The ORs for success can be construed as ORs for failure by switching the reference group (e.g. Diabetes mellitus (present vs. absent)).

This article is protected by copyright. All rights reserved. 
Figure 1 Success rate $(\%)$ of root canal treatment $(\mathrm{RCT})$ according to systemic diseases and preoperative periapical status. $\mathrm{DM}=\mathrm{Diabetes}$ mellitus, CVD =

Cardiovascular disease, Other immunosuppression $=$ Patients with autoimmune disease, cancer or immunosuppressive medication, NAP= no apical periodontitis, AP = apical periodontitis. Statistical evaluation by means of a. Fisher's exact tests or b. Chi-squared tests.

This article is protected by copyright. All rights reserved. 


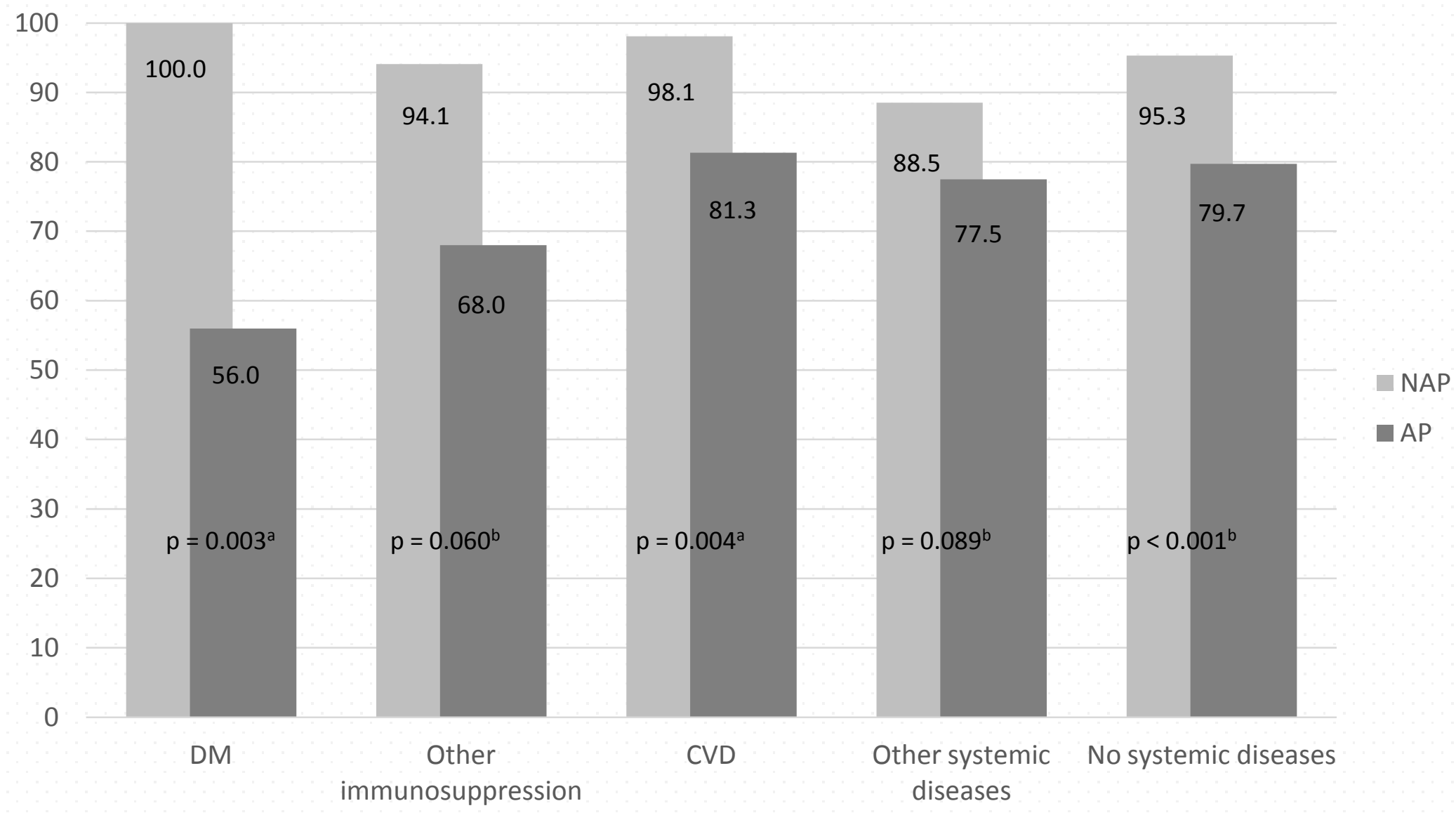

Figure 1. Success rate (\%) of root canal treatment (RCT) according to systemic diseases and preoperative periapical status.

$\mathrm{DM}=$ Diabetes mellitus, $\mathrm{CVD}=$ Cardiovascular disease, $\mathrm{NAP}=$ no apical periodontitis, $\mathrm{AP}=$ apical periodontitis. Statistical evaluation by means of a Fisher's exact tests or ${ }^{b}$ Chi-squared tests.

This article is protected by copyright. All rights reserved. 